\title{
Litter quality and temperature modulate microbial diversity effects on decomposition in model experiments
}

\author{
G. Bonanomi ${ }^{1}$, M. Capodilupo, G. Incerti, S. Mazzoleni and F. Scala \\ Dipartimento di Agraria, Università di Napoli Federico II, via Università 100, Portici 80055 (NA), Italy \\ ${ }^{1}$ Corresponding author.E-mail: giuliano.bonanomi@unina.it.Tel.: +39081 2539015, Fax: +390817760104
}

Keywords: Biodiversity-ecosystem function, Decomposition, Ecosystem stability, Microbial diversity, Niche partitioning, Sampling effect.

\begin{abstract}
The consequences of decline in biodiversity for ecosystem functioning is a major concern in soil ecology. Recent research efforts have been mostly focused on terrestrial plants, while, despite their importance in ecosystems, little is known about soil microbial communities. This work aims at investigating the effects of fungal and bacterial species richness on the dynamics of leaf litter decomposition. Synthetic microbial communities with species richness ranging from 1 to 64 were assembled in laboratory microcosms and used in three factorial experiments of decomposition. Thereafter, the functionality of the different microcosms was determined by measuring their capability to decompose materials with different chemical properties, including two species of litter (Quercus ilex L. and Hedera helix L.), cellulose strips and woody sticks. Incubation was done in microcosms at two temperatures $\left(12^{\circ} \mathrm{C}\right.$ and $\left.24^{\circ} \mathrm{C}\right)$ for 120 days. The number of microbial species inoculated in the microcosms positively affected decomposition rates of $Q$. ilex and $H$. helix litters, while relationships found for cellulose and wood were not statistically significant. Diversity effect was greater at higher incubation temperature. We found lower variability of decay rates in microcosms with higher inoculated species richness of microbial communities. Our study pointed out that the relationships between inoculum microbial diversity and litter decomposition is dependent on temperature and litter quality. Therefore, the loss of microbial species may adversely affects ecosystem functionality under specific environmental conditions.
\end{abstract}

Abbreviations: BEF-Biodiversity-Ecosystem Function, GLM-Generalized Linear Model.

\section{Introduction}

Plant litter decomposition is a key process for terrestrial ecosystem functioning, providing nutrient release, contributing to soil organic matter formation, and affecting carbon balance. Decay rates undergo abiotic control mainly by temperature and litter moisture (Aerts 1997), as well as litter chemical quality (Berg and McClaugherty 2008). Besides, high diversity of microbial decomposers and invertebrate detritivores, forming complex food webs, concur to litter decomposition (Hättenschwiler et al. 2005). As a consequence, litter inputs and dynamics can strongly affect multiple trophic levels in different ecosystems (Wallace et al. 1997). Many studies described the composition of invertebrate detritivores (Merritt and Lawson 1992), bacterial (Dilly et al. 2004) and fungal (Frankland 1998) decomposer communities, but less attention has been paid to their functional dynamics (Hättenschwiler et al. 2005).

Investigation of the relationships between species diversity and ecosystem functioning has received growing attention in recent years, and it is now well recognized that biodiversity strongly affects ecosystem processes such as productivity (Tilman et al. 2001), stability (Mulder et al. 2001) and invasibility (Dukes 2001). However, available studies focused mostly on terrestrial plants, with less attention paid to soil microbial communities (Hooper et al. 2005), despite their importance both in natural and human managed ecosystems. The use of synthetically assembled communities, originally developed to assess the biodiversity-ecosystem function (BEF) in terrestrial ecosystems (e.g., Naeem et al. 1994, Tilman et al. 1996), is increasingly applied also to microbial systems (Jiang and Morin 2005, Bell et al. 2005). This approach, by using well-controlled model systems, allows a complete control of environmental conditions and diversity level of microbial communities. However, the synthetically assembled communities have the drawback that only a minor fraction of soil microbes is culturable in laboratory, thus limiting the representativeness of natural communities. In the last years an increasing effort was addressed to study the BEF in the context of soil functions (Griffiths et al. 2000, Tiunov and Scheu 2005). However, many studies used over-simplified systems with a low species number (usually less than 10 species) with respect to natural systems (e.g., Frankland 1966, Dilly et al. 2004), and a short time frame compared to the majority of the decomposition experiments (Berg and McClaugherty 2008). In addition, a large fraction of such studies were done in freshwater systems using hyphomycete fungi (Bärlocher and Corkum 2003, Dang et al. 2005, Duarte et al. 2006, Costantini and Rossi 2010), while relatively few studies were carried-out in terrestrial ecosystems using both fungi and bacteria (Setälä and McLean 2004). 
Since the early 1990 's, evidence obtained from laboratory and field experiments has shown that increasing biodiversity tends to have positive effects on ecosystem properties. However, the response pattern often varies depending on the ecosystem, the species investigated and the underlying ecological conditions (Hooper et al. 2005). Many experiments testing the BEF have been often carried out by selecting a single set of constant environmental conditions, thus making applicability to the real world questionable (Srivastava and Vellend 2005). The inherent complexity of environmental systems requires more realistic experimental designs to clarify if the currently observed patterns in the BEF relationship apply to natural scenarios and over larger spatial and temporal scales (Replansky and Bell 2009). Consequently, to assess the general validity of the BEF relationships, the use of synthetically assembled microbial communities that include environmental complexity is a promising approach (Langenheder et al. 2010). Although litter quality and temperature are obviously two key factors affecting litter decomposition (Berg and McClaugherty 2008), we are not aware of studies explicitly incorporating such effects into the BEF framework.

The general aim of this study is to explore how BEF changes during litter decomposition and its dependence on litter chemical quality and temperature. We used synthetically assembled microbial communities with high complexity, ranging from monospecific up to 64 species, and applied them to different plant materials that encompass a wide range of chemical quality (Hedera helix L. and Quercus ilex L. leaf litter, cellulose strips and woody sticks) incubated under two environmental scenarios with low and high temperatures. Specifically, we tested if (1) litter decomposition rates increase as microbial diversity increases; (2) diversity effects depend on litter quality, temperature and duration of decomposition; and (3) variability in decomposition rates decreases as microbial diversity increases.

\section{Methods}

\section{Microbial species}

Thirty-two bacterial and thirty-two fungal strains (see Supplementary Tables S1 and S2) were obtained from the collection of the Dipartimento di Agraria and, in part, isolated from two Italian soils: i) a volcanic ash soil from a natural oldgrowth holm oak forest located on Vesuvius southern slope (Portici, Naples 40 48' 43" N - 14 20' 49" E, Southern Italy) and ii) an agricultural sandy soil. For soil characterization see Bonanomi et al. (2010, 2011a).

Culturable bacteria and fungi were isolated on different agar media. Soil suspensions were prepared from soil samples by shaking (200 rpm) $5 \mathrm{~g}$ of sieved soil with $50 \mathrm{ml}$ of sterile physiological solution $(\mathrm{NaCl} 0.9 \% \mathrm{w} / \mathrm{v})$ for $30 \mathrm{~min}$ at room temperature. After this phase, soil mixtures were left standing for $10 \mathrm{~min}$. Volumes of $100 \mu \mathrm{l}$ were then serially diluted and plated over different media. For fungi we used two substrates: i) water agar (WA) amended with chloramphenicol
$(50 \mathrm{ppm})$ and streptomycin $(50 \mathrm{ppm})$; ii) potato dextrose agar (PDA) amended with lactic acid (25\%). Antibiotics or lactic acid were used to prevent bacterial growth. R2A agar medium (Fluka) amended with cycloheximide at $100 \mathrm{ppm}$, in order to prevent fungal growth, was used for bacteria. Antibiotics and lactic acid were used only for microbes selection but not in microcosms experiments. Identities for both gram-negative and gram positive bacteria were assigned to bacterial isolates using the BiologTM Microbial ID system, specifically the MicroPlate microbial identification system (Biolog, Inc., Hayward, California, USA). This tool has been proven able to resolve bacterial identities at the species level with accuracy comparable to the far more expensive gold standard based on 16S rRNA gene sequencing (Wragg et al. 2014). Fungi were identified analyzing specific morphological characteristics (i.e., colony, hyphae, fruiting structures). For species not identifiable by the morphological method, we used a genetic analysis by sequencing the internal transcribed spacers (ITS15.8S-ITS2) following the method of White et al. (1990) with some modifications. Briefly, fungal spores were inoculated in PDB (Potato Dextrose Broth, Sigma) and incubated at $25^{\circ} \mathrm{C}$ on an orbital shaker (250 rpm) for five days. Fungal biomass was harvested by separating the substrate for filtration with paper Miracloth (Calbiochem, Merck Millipore, Darmstadt, Germany), washed repeatedly with sterile distilled water and dried with paper towels. The mycelium was first held at $-20^{\circ} \mathrm{C}$ for 24 hours and then placed in $50 \mathrm{ml}$ polypropylene tubes to freeze-dry. The lyophilized biomass was pulverized with the aid of a spatula and subjected to DNA extraction. One gram of lyophilized mycelium was suspended in $10 \mathrm{ml}$ of extraction buffer $(0.5 \mathrm{M} \mathrm{NaCl}, 10 \mathrm{mM}$ Tris-HCl, $10 \mathrm{mM}$ EDTA, $1 \% \mathrm{SDS} \mathrm{pH} 7.5$ ), to which $5 \mathrm{ml}$ of phenol and $5 \mathrm{ml}$ of chloroform-isoamyl alcohol (24:1) were added. The suspension was gently stirred and then centrifuged at $4{ }^{\circ} \mathrm{C}$ for 30 minutes at $12000 \mathrm{rpm}$. The recovered aqueous phase was digested with $50 \mu \mathrm{l}$ of RNase $(10 \mathrm{mg} / \mathrm{ml})$ for 1 hour at $37^{\circ} \mathrm{C}$. After the digestion $10 \mathrm{ml}$ of phenol-chloroform was added, the sample was gently shaken and centrifuged again. The aqueous phase was subjected to two further extractions, first with phenolchloroform and then with chloroform, respectively. The recovered aqueous phase (containing the genomic DNA) was added with isopropanol and centrifuged at room temperature for 15 minutes. The pellet obtained was washed with $70 \%$ ethanol, placed to dry and then resuspended in T3E $(10 \mathrm{mM}$ Tris - EDTA 10 mM, pH 8.0). The DNA obtained was quantified by electrophoresis on agarose gel for comparison with a standard DNA ladder. The PCR was performed with the use of SR6R primer (5'-AAGTAGAAGTCGTAACAAGG-3 ') and LR1 (5'-GGTTGGTTTCTTTTCCT-3'), fragments which contain the ITS regions: ITS 1 (ITS-1), the 5, 8 S rDNA and the ITS-2. For PCR the following parameters were used: denaturation at $94^{\circ} \mathrm{C}$ for 2 minutes, 30 cycles of amplification 30 seconds of denaturation at $94^{\circ} \mathrm{C}, 45$ seconds annealing of primers at $50^{\circ} \mathrm{C}, 60$ seconds of elongation at $72^{\circ} \mathrm{C}$ and a final elongation of 10 minutes at $72^{\circ} \mathrm{C}$. The PCR products were separated by electrophoresis in agarose gel for quantification and to establish the specificity of the PCR. Sequencing was 
carried out at GENOPOM research centre (Department of Agriculture, University Federico II of Naples).

\section{Plant materials and organic substrates}

Four materials were selected to represent a wide range of chemical quality: i) Hedera helix leaf litter, a fast decomposing evergreen vine; ii) Quercus ilex leaf litter, a slow decomposing evergreen tree (Bonanomi et al. 2013); iii) woody sticks cut from living $Q$. ilex branches; and iv) cellulose strips (Whatman filter paper). Freshly abscissed leaves were collected by nets placed under plants from natural communities (no. of plants $>20$ for each species), dried $\left(60^{\circ} \mathrm{C}\right.$ in a ventilated chamber until constant weight was reached), and then stored at room temperature. Undecomposed litter was characterized for total $\mathrm{C}$ and $\mathrm{N}$ content by flash combustion of microsamples (5 mg of litter) in an Elemental Analyser NA 1500 (Carlo Erba Strumentazione, Milan, Italy). The content of acid-detergent hydrolysable fibre (thereafter indicated as labile C), proximate cellulose and lignin were assessed following the procedure described by Gessner (2005). Briefly, labile $\mathrm{C}$ was determined by mild acid hydrolysis with $0.5 \mathrm{M}$ $\mathrm{H}_{2} \mathrm{SO}_{4}$ added with the detergent cetyltrimethylammonium $\left(\mathrm{CTAB}, 20 \mathrm{~g} \mathrm{l}^{-1}\right)$, proximate cellulose was determined as hydrolysable fraction after drastic sulphuric acid treatment (loss due to $72 \% \mathrm{H}_{2} \mathrm{SO}_{4}$ for 3 hours), and proximate lignin as the unhydrolyzable fraction (loss upon ignition after the above mentioned $\mathrm{H}_{2} \mathrm{SO}_{4}$ treatment). It is important to note that the lignin assessed in this way does not correspond to pure lignin because it may include some other hydrolysis-resistant organic structures, such as cutin, waxes, and condensed tannins at varying proportions. All carbon fractions are presented as ash-free dry mass.

\section{Decomposition experiments}

Decomposition experiments were carried out in microcosms designed to simulate litter decomposition in terrestrial conditions. Microcosms consisted of $300 \mathrm{ml}$ polycarbonate Magenta vessel (Sigma-Aldrich, Co. LLC.) with polypropylene aerated lid. Air dried leaf litter discs, woody sticks and cellulose strips were cut by scissors to obtain pieces of 100 $\mathrm{mg}$. Batches with 9 pieces of each material were introduced into microcosms and twice autoclaved to remove pre-existing microbial community before exposure to experimental treatments. In all experiments, microcosms were kept under controlled conditions at two temperatures $\left(12^{\circ} \mathrm{C}\right.$ and $\left.24^{\circ} \mathrm{C}\right)$ and not limiting water (watered every seven days with sterile distilled water). Experiments were run for 120 days and litters were harvested after 10, 40 and 120 days of decomposition. Collected litters were oven-dried at $60^{\circ} \mathrm{C}$ until constant weight was reached and then weighted to the nearest $0.001 \mathrm{~g}$.

Concerning microbial inoculum, three experiments were carried out. The first included fungi, the second bacteria, and the third fungi and bacteria simultaneously. In the first and second experiments four levels of species richness were used (1, 2, 8 and 32 species), while in the third experiment five levels were used $(1,2,8,32$ and 64 species). In the third experi- ment at each diversity level, the number of bacterial and fungal species were the same (i.e., in the case of consortia with eight species, four were bacteria and four fungi). Microbial combinations were randomly assembled because it is logistically not feasible to produce all possible combinations of 32 and 64 species (Bell et al. 2005). With the exception of the most diverse treatment that was replicated two times with the same species combination, in each diversity treatment, microbial species were randomly chosen from the species pool. Random assemblage is a crucial requisite of the experimental design to effectively test the effect of diversity on ecosystem functions and excluding confounding factors (Huston 1997). The species combinations included all monospecific microcosms ( 32 for the first and second experiments and 64 for the third one) and eight replications at all other diversity levels (see Tables S3 and S4). The use of such biodiversity experimental design, that includes all monospecific microcosms, enables the assessment of the "species sampling effect" $v S$ "species complementarity effect" because the performance of multiple species mixture can be compared with that of the most effective monoculture (Huston 1997, Wardle 1999). The complete experimental design consisted of 400, 400, and 720 microcosms in the first, second and third experiment, respectively. Totally, 13,680 pieces of litter were analyzed for mass loss. Because of the large number of microcosms $(n=1520)$, the assessment of realized species richness was logistically and economically not feasible. We acknowledge that assessing realized species richness in all microcosms at the end of the experiment is of great relevance for a proper understanding on the role of microbial diversity. Our study, however, allows a direct comparison of microbial inoculums with different initial species richness.

Microcosms were inoculated keeping constant the amount of fungal spores and bacterial cells at each diversity level. Moreover, all experiments were designated to start with a relatively low inoculum level $\left(1 \times 10^{4}\right.$ spores for fungi and $1 \times 10^{5}$ cells for bacteria) to reproduce a realistic colonization of the organic substrates. For microcosms with more than 1 species, the number of spores/cells inoculated for each species were reduced in proportion to the species number of consortia (i.e., in case of consortia with four species, each fungal species contribute with an amount of $2.5 \times 10^{3}$ spores for a total amount of $1 \times 10^{4}$ spores). Fungal inoculum was obtained from ten days old culture grown over PDA. Ten ml of sterile water was added to such cultures and the surface was scraped to remove spores. The suspension was filtered, centrifuged, washed twice with sterile water and adjusted to a concentration of $10^{5}$ spores $\mathrm{ml}^{-1}$ by hemocytometer. Inoculum was obtained by the addition of $500 \mu$ of these spores suspensions adjusted as before described. Bacterial inoculum was obtained from pure cultures refreshed over nutrient agar broth (NA) for three days at $20^{\circ} \mathrm{C}$. Subsequently, bacterial cultures were centrifuged and refreshed with sterile physiological solution. In order to obtain the desired bacterial concentrations, density of liquid culture was spectrophotometrically evaluated $(\lambda=530 \mathrm{~nm})$ and, thereafter, adjusted by dilution.

Microcosms contamination was checked at every harvesting date (i.e., after 10, 40 and 120 days of decomposition) 
Table 1. Relative content of proximate and elemental chemical parameters of plant materials examined. Values are the average of three replicates. Different letters within each row indicate statistically significant differences (Tukey's HSD post-hoc test, $\mathrm{p}<0.05$ ). Labile $\mathrm{C}$, cellulose and lignin content are expressed as ash free relative value of total structure.

\begin{tabular}{lrrrr}
\hline & \multicolumn{4}{c}{ Organic substrate } \\
\cline { 2 - 5 } & Hedera helix & Quercus ilex & Wood & Cellulose \\
\hline Proximate chemical parameters & & & & \\
Labile C (\%) & $70.5 \mathrm{a}$ & $58.5 \mathrm{~b}$ & $13.8 \mathrm{c}$ & - \\
Cellulose (\%) & $23.8 \mathrm{~b}$ & $22.7 \mathrm{~b}$ & $49.5 \mathrm{a}$ & - \\
Lignin (\%) & $5.7 \mathrm{c}$ & $18.8 \mathrm{~b}$ & $36.7 \mathrm{a}$ & - \\
& & & & \\
Elemental chemical parameters & & & & \\
Nitrogen (\%) & $2.0 \mathrm{a}$ & $1.24 \mathrm{~b}$ & $0.11 \mathrm{c}$ & $0.08 \mathrm{~d}$ \\
Carbon (\%) & $45.1 \mathrm{a}$ & $46.5 \mathrm{a}$ & $47.34 \mathrm{a}$ & $48.56 \mathrm{a}$ \\
C / N ratio & $22.5 \mathrm{~d}$ & $37.5 \mathrm{c}$ & $430.4 \mathrm{~b}$ & $607.0 \mathrm{a}$ \\
Lignin / N ratio & $2.8 \mathrm{c}$ & $14.8 \mathrm{~b}$ & $314.5 \mathrm{a}$ & - \\
\hline
\end{tabular}

by microscopic observation of presence of fungal structures (spores, hyphae) and bacterial colonies. In addition, for randomly selected microcosms, isolation of fungi and bacteria was carried out from different organic substrates. In detail, litter material was plated over different semi-selective substrates (WA, PDA, PDA with lactic acid and R2A) and checked for the occurrences of inoculated species.

\section{Data analysis}

For all three experiments, data were transformed using either arcsine or squared root functions to satisfy the assumptions of normality and homogeneity of variance, and submitted to General Linear Models (GLM) analysis, using the software STATISTICA 7 (StatSoft Inc.). Percent mass loss of litter samples, expressed as percentage of initial mass, was considered as the dependent variable. Main and second order interactive effects of temperature (2 levels), species richness $(4,4$, and 5 levels for inoculation with bacterial, fungal, and mixed communities, respectively), substrate type (4 levels), and decomposition time (continuous variable) were considered. Pairwise differences were tested using Tukey's HSD post-hoc test.

\section{Results}

\section{Plant materials biochemical quality}

Content of initial litter nitrogen, labile $\mathrm{C}$, lignin and $\mathrm{C} / \mathrm{N}$ and lignin/ $\mathrm{N}$ ratios significantly varied among the four materials (Table 1). Concentrations of $\mathrm{N}$ and labile $\mathrm{C}$ were the highest for H. helix and Q. ilex and lowest for woody sticks and cellulose strips (Table 1). This trend was the opposite for lignin, $\mathrm{C} / \mathrm{N}$ and lignin/ $\mathrm{N}$ ratios with highest values for woody sticks and lowest for $H$. helix. Cellulose content was higher for woody sticks compared to the two litter types (Table 1).

\section{Effects of temperature and litter quality on decomposition}

Overall, treatments significantly affected mass loss of the tested materials in all three decomposition experiments, which differed by the type of microbial inoculum and produced highly fitting linear models (adjusted $\mathrm{R}^{2}$ was higher than 0.85 in all experiments, Table 2). In particular, highly significant first order effects of litter quality, decomposition time and temperature were found (Table 2). Mass loss largely varied among the four different organic substrates (S) and, for each material, over time (D), with significant interaction terms $\mathrm{S} \times \mathrm{D}$ (Table 2) indicating differences increasing over time (Fig. 1). Mass loss was the highest for $H$. helix, intermediate for $Q$. ilex and, obviously, much lower for woody sticks and cellulose strips (Fig. 1). As decomposition proceeded, mass loss rate declined for the two leaf litter types (Fig. 1). Mass loss significantly increased with temperature for all materials, with $\mathrm{Q}_{10}$ values (average \pm standard deviation) of $1.81 \pm 0.06,1.64 \pm 0.05,1.34 \pm 0.17,1.32 \pm 0.15$ for $H$. helix, $Q$. ilex, woody sticks and cellulose, respectively. For all types of microbial inoculum, significant second order effects of temperature with substrate type $(\mathrm{T} \times \mathrm{S}$, Table 2$)$ and decomposition time $(\mathrm{T} \times \mathrm{D}$, Table 2$)$ corresponded to a synergistic interactions (Fig. 1).

\section{Effects of microbial diversity on decomposition}

Overall, the effect of fungal or bacterial species richness on substrate mass loss was not statistically significant (Table 2). However, both bacterial and fungal richness showed significant interactions with substrate quality, temperature and decomposition time (Table 2). Inoculum species richness, for both bacteria and fungi, did not affect mass loss of woody stick and cellulose strips both at $12^{\circ} \mathrm{C}$ and $24^{\circ} \mathrm{C}$ (Fig. 2). Differently, the effect of bacterial or fungal inoculum species richness was significant for the two leaf litter types $(Q$. ilex and H. helix) at the highest temperature (Fig. 3). With bacteria, a strong positive effect of species richness on mass loss was found only for $H$. helix at $24^{\circ} \mathrm{C}$ (Fig. 3). Considering all the experimental conditions, the best multi-species fungal communities outperformed the best monocultures, in terms of recorded mass loss, only in three out of twelve cases for fungi, while the best multi-species bacterial communities never outperformed the best monocultures. Contamination by not inoculated microbes was very low in the case of fungal 
Table 2. General Linear Modeling (GLM) of mass loss from three decomposition experiments differing by type of microbial inoculum. Data refer to univariate testing for main and second order interactive effects of temperature (two levels: $12^{\circ} \mathrm{C}$ and $24^{\circ} \mathrm{C}$ ), species richness of microbial inoculum (four levels in all experiments: 1, 2, 8, 32 species, and an additional level with 64 species in the experiment with mixed fungal and bacterial inoculum), organic substrate type (four levels: leaf litter of Hedera helix and Quercus ilex, cellulose strips, woody sticks), and decomposition time (continuous variable). Adjusted $\mathrm{R}^{2}$ for the three models with bacterial, fungal, and mixed inoculums were $0.8618,0.9091$, and 0.9129 , respectively.

\begin{tabular}{lrrrrr}
\hline & SS & d.f. & \multicolumn{1}{c}{ MS } & \multicolumn{1}{c}{$\mathrm{F}$} & $\mathrm{p}$ \\
\hline Bacteria & & & & & \\
Temperature (T) & 1504.86 & 1 & 1504.86 & 87.55 & $<0.0001$ \\
Species richness (R) & 83.45 & 3 & 27.82 & 1.62 & 0.1835 \\
Substrate type (S) & 17200.44 & 3 & 5733.48 & 333.58 & $<0.0001$ \\
Decomposition time (D) & 1282.48 & 1 & 1282.48 & 74.62 & $<0.0001$ \\
$\mathrm{~T} \times \mathrm{R}$ & 187.67 & 3 & 62.56 & 3.64 & 0.0125 \\
$\mathrm{~T} \times \mathrm{S}$ & 8923.74 & 3 & 2974.58 & 173.06 & $<0.0001$ \\
$\mathrm{R} \times \mathrm{S}$ & 365.67 & 9 & 40.63 & 2.36 & 0.0122 \\
$\mathrm{~T} \times \mathrm{D}$ & 256.06 & 1 & 256.06 & 14.90 & 0.0001 \\
$\mathrm{R} \times \mathrm{D}$ & 106.43 & 3 & 35.48 & 2.06 & 0.1034 \\
$\mathrm{~S} \times \mathrm{D}$ & 3062.25 & 3 & 1020.75 & 59.39 & $<0.0001$ \\
\hline Fungi & & & & & \\
Temperature (T) & 1213.62 & 1 & 1213.62 & 49.30 & $<0.0001$ \\
Species richness (R) & 144.11 & 3 & 48.04 & 1.95 & 0.1196 \\
Substrate type (S) & 29969.55 & 3 & 9989.85 & 405.82 & $<0.0001$ \\
Decomposition time (D) & 1864.12 & 1 & 1864.12 & 75.73 & $<0.0001$ \\
$\mathrm{~T} \times \mathrm{R}$ & 366.98 & 3 & 122.33 & 4.97 & 0.0020 \\
$\mathrm{~T} \times \mathrm{S}$ & 7579.74 & 3 & 2526.58 & 102.64 & $<0.0001$ \\
$\mathrm{R} \times \mathrm{S}$ & 1154.67 & 9 & 128.30 & 5.21 & $<0.0001$ \\
$\mathrm{~T} \times \mathrm{D}$ & 110.57 & 1 & 110.57 & 4.49 & 0.0343 \\
$\mathrm{R} \times \mathrm{D}$ & 183.73 & 3 & 61.24 & 2.49 & 0.0591 \\
$\mathrm{~S} \times \mathrm{D}$ & 13706.28 & 3 & 4568.76 & 185.60 & $<0.0001$ \\
\hline Bacteria and Fungi & & & & & \\
Temperature (T) & 3403.74 & 1 & 3403.74 & 186.10 & $<0.0001$ \\
Species richness (R) & 278.51 & 4 & 69.63 & 3.81 & 0.0044 \\
Substrate type (S) & 19597.47 & 3 & 6532.49 & 357.16 & $<0.0001$ \\
Decomposition time (D) & 13382.10 & 1 & 13382.10 & 731.67 & $<0.0001$ \\
$\mathrm{~T} \times \mathrm{R}$ & 354.86 & 4 & 88.72 & 4.85 & 0.0007 \\
$\mathrm{~T} \times \mathrm{S}$ & 23699.78 & 3 & 7899.93 & 431.93 & $<0.0001$ \\
$\mathrm{R} \times \mathrm{S}$ & 3339.78 & 12 & 278.31 & 15.22 & $<0.0001$ \\
$\mathrm{~T} \times \mathrm{D}$ & 973.26 & 1 & 973.26 & 53.21 & $<0.0001$ \\
$\mathrm{R} \times \mathrm{D}$ & 35.63 & 4 & 8.91 & 0.49 & 0.7453 \\
$\mathrm{~S} \times \mathrm{D}$ & 24023.46 & 3 & 8007.82 & 437.83 & $<0.0001$ \\
\hline & & & & &
\end{tabular}
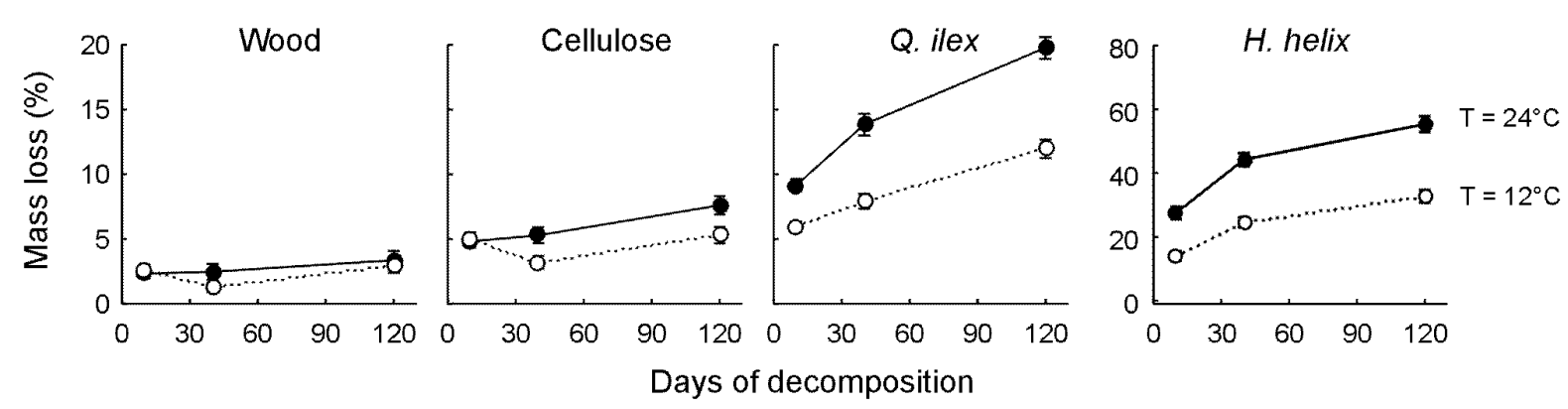

Figure 1. Synergistic second order effects of temperature (two levels: $12^{\circ} \mathrm{C}$ and $24^{\circ} \mathrm{C}$, open and filled symbols, respectively) and decomposition time (three levels: 10, 40, and 120 days) on decomposition dynamics of four organic substrates. Data refer to mean and confidence intervals $(\mathrm{N}=190)$ of mass loss (percent of initial mass) observed in decomposition experiments combining different type (bacterial, fungal, or mixed) and species richness (1, 2, 8, 32, and 64 species) of microbial inoculum.

communities (overall $0.6 \%$ ), while with bacterial communities, incubated at $24^{\circ} \mathrm{C}$ on both litter types, it was relevant after 120 days $(11 \%$ and $13 \%$ for $Q$. ilex and H. helix, respectively).

When bacteria and fungi where co-inoculated, diversity effect on substrate mass loss was statistically significant but, even in this case, dependent on litter quality and temperature (Table 2). Microbial diversity showed a strong positive effect on mass loss of H. helix only at the highest incubation temperature (Fig. 3). However, diversity effect was linear after
40 days of decomposition, while at the early and late stages of decomposition hump-shaped responses to increasing species richness were observed, with higher litter mass loss for microbial consortia with 8 species compared to communities composed of 1, 2, 32 and 64 species (data not shown). Such differences were still detectable when data were pooled for all decomposition stages, but were not statistically significant, with the exception of monospecific vs multi-species inoculums (Fig. 3). At the lowest temperature, H. helix mass loss was not significantly affected by the inoculum species 
Figure 2. Effects of microbial species richness on organic substrate decomposition, in presence of either bacterial, fungal, or mixed microbial communities (from left to right, respectively). Boxwhisker plots show mean, standard error and standard deviation of mass loss (percent of initial mass) from two organic substrates (cellulose strips and woody sticks, top and bottom, respectively). Data are pooled for two incubation temperatures $\left(12^{\circ} \mathrm{C}\right.$ and $24^{\circ} \mathrm{C}$ ) and three decomposition periods $(10,40$, and 120 days). F statistics refer to one-way ANOVA for species richness.

Figure 3. Temperature- and litter quality-dependent effects of microbial species richness on leaf litter decomposition, in presence of either bacterial, fungal, and mixed microbial inoculum (from left to right, respectively). Data refer to mean, standard error and standard deviation of mass loss (percent of initial mass) observed at two incubation temperatures $\left(12^{\circ} \mathrm{C}\right.$ and $24^{\circ} \mathrm{C}$ ) for two litter types.
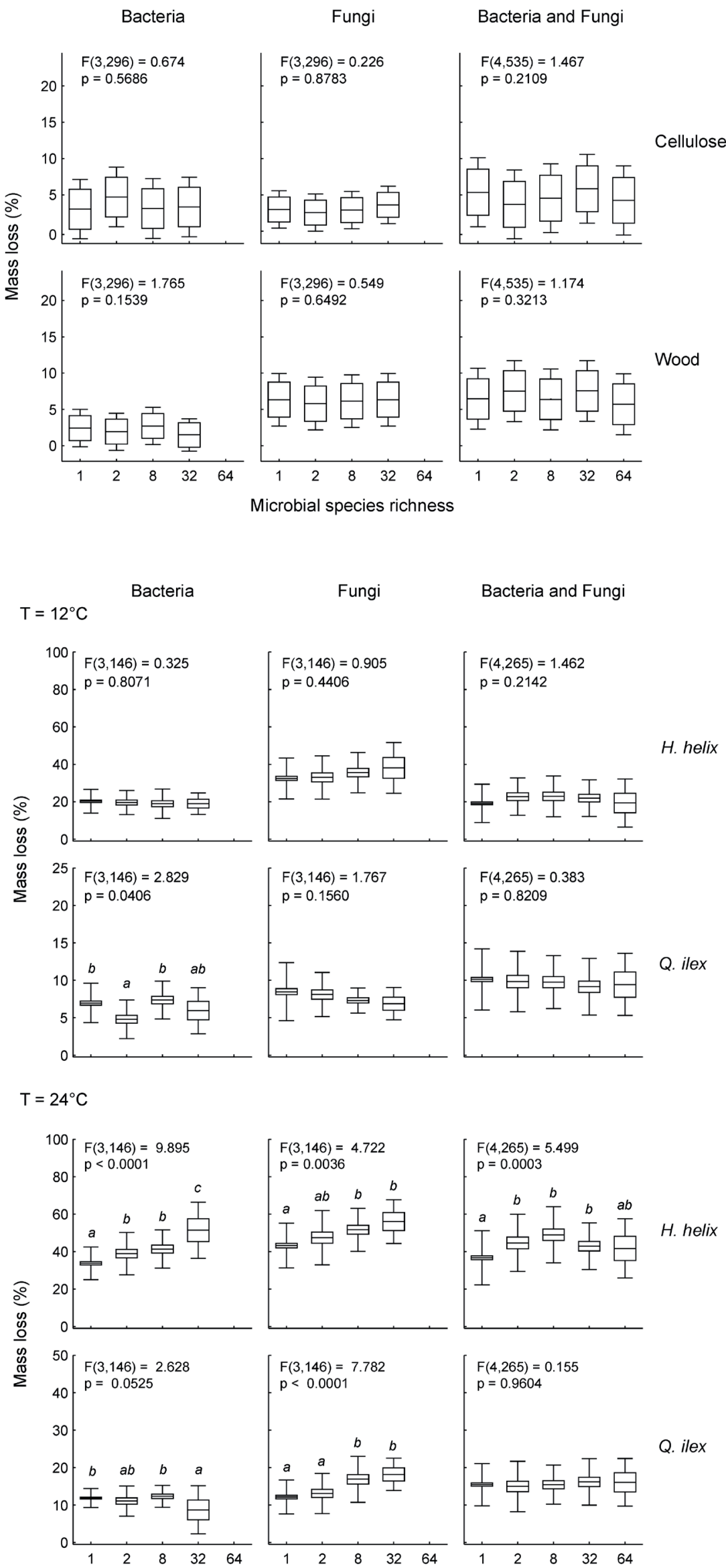


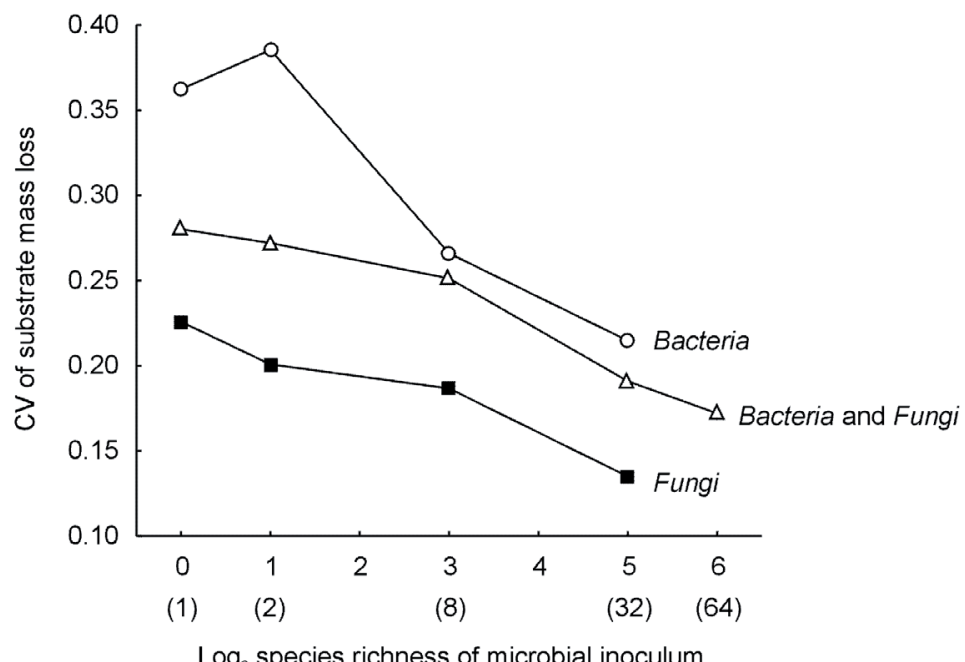

Figure 4. Relationship between microbial species richness (tested values in brackets) and coefficient of variation (CV) of leaf litter mass loss, in presence of either bacterial or fungal, and mixed microbial inoculum. Data refer to mean of mass loss (percent of initial mass) observed after 120 days of decomposition at two incubation temperatures $\left(12^{\circ} \mathrm{C}\right.$ and $\left.24^{\circ} \mathrm{C}\right)$ for two litter types (Hedera helix, Quercus ilex).

richness. Q. ilex litter, when exposed to mixed bacterial and fungal inoculums, was not affected by microbial species richness, showing not statistically significant relationship at both temperatures of incubation (Fig. 3). Effects of microbial species richness on mass loss of woody sticks and cellulose strips were not statistically significant, irrespectively of the incubation temperature. Considering all the experimental conditions, the best multi-species microbial communities outperformed the best monocultures only in three out of twelve cases and only when $H$. helix was incubated at $24^{\circ} \mathrm{C}$. The incidence of contamination was dependent on temperature and litter quality. Contamination was higher at $24^{\circ} \mathrm{C}$ compared to $12^{\circ} \mathrm{C}(12 \%$ and $4 \%$, respectively) and for $H$. helix compared to $Q$. ilex and woody sticks $(13 \%, 11 \%$ and $9 \%$, respectively).

\section{Microbial diversity and decomposition stability}

The stability of litter decomposition, expressed as coefficient of variation (CV) of litter mass loss, was assessed as a function of species richness of microbial inoculum in microcosms (Fig. 4). The variability of the process rate consistently decreased by increasing species richness, for all types of inoculum (either bacteria, fungi, or bacteria and fungi co-inoculated), except for bacterial monocultures, which on average showed a slightly lower CV compared to the two-species sets (Fig. 4). At each species richness level, bacterial and fungal communities showed the lowest and the highest $\mathrm{CV}$, respectively, while multi-species communities consistently showed intermediate values (Fig. 4).

\section{Discussion}

Microbial diversity may have positive, no significant or even negative relationships on litter mass loss (Bärlocher and Corkum 2003, Dang et al. 2005, Tiunov and Scheu 2005, Bell et al. 2005, Jiang 2007, Replansky and Bell 2009, Costantini and Rossi 2010). This variability is confirmed by the results of our study, where BEF relationships were dependent on the ecological context and related to litter quality, incubation temperatures and duration of the decomposition process. The variable relationships between inoculated microbial diversity and litter mass loss suggests that litter decomposition is a process less affected by the number of microbial species (Dang et al. 2005), compared to primary plant productivity (Tilman et al. 2001, Hooper et al. 2005).

The effects of species diversity on litter mass loss are influenced by facilitative as well as competitive interactions between microbes, resulting in additive or synergistic net effects. Additive effect can be related to niche partioning while interspecific facilitation is a possible underlying mechanism for synergistic effects. Spatial and temporal niche partitioning may occur when microbes colonize different litter microhabitats, as frequently it is observed during microbial successions which follow biochemical changes in organic matter (Frankland 1998). For instance, some saprotrophic "sugar" fungi (Garrett 1963) that thrive when simple sugar is abundant, but are unable to decompose more complex C compounds (e.g., cellulose and lignin), can be found on these recalcitrant substrates because they are able to use metabolism by-products of lignin decomposer fungi (Berg and McClaugherty 2008). In competitive interactions, instead, litter decomposition by multi-species microbial consortia can be slower, compared to monoculture, because microbes release antimicrobial compounds that negatively affect species with higher saprobic capacities. Strong interspecific antagonistic interactions have been observed among saprotrophic fungi (Boddy 2000) and between bacteria and fungi (Romaní et al. 2006).

In our experiments, the occurrence of either competitive or synergistic microbe interactions may explain the retarded 
or accelerated litter decomposition displayed by multi-species microbial consortia compared to monoculture. The cooccurrence of bacteria and fungi in synthetically assembled communities affects BEF because diversity effects were clearly different when bacteria and fungi were independently or simultaneously inoculated. In experiments where fungi and bacteria where co-inoculated, at the highest temperature, positive and not significant diversity-decomposition relationships with $H$. helix and $Q$. ilex, respectively, were observed. In contrast, when only fungi where inoculated, diversitydecomposition relationships were mostly positive with both litter types. The effects observed with inoculated species mixtures could be due to competition between bacteria, that usually have a lower saprobic capacities, and fungi. It is possible that fast growing bacteria firstly deplete the small amount of simple C compounds; thereafter, the presence of living bacteria and their inhibitory metabolites (Weller et al. 2002) could prevent the successional replacement by cellulolytic and ligninolytic fungi that possess the enzymatic arsenal to attack recalcitrant organic substrates (Moorhead and Sinsabaugh 2006, Berg and McClaugherty 2008). Osono (2003) reported that prior colonization by phyllosphere microbes can retard subsequent beech leaf litter decomposition by saprotrophic specialized fungi. In contrast with results reported for $Q$. ilex, over H. helix that initially is rich in labile $\mathrm{C}$ compounds, fungi and bacteria seem to cooperate in the early phase of decomposition process. However, it is well known that plant litter, initially rich in labile $\mathrm{C}$ compounds, as decomposition proceeds, becomes progressively more resistant to microbial decomposition because of the relative increase of lignin (Preston et al. 2009). In other words, heterotrophic microbes, by using organic substrates, progressively change their biochemical quality (Swift et al. 1979) that, in turn, drives microbial succession (Rinkes et al. 2011). In the case of the fast decomposing $H$. helix litter, we previously demonstrated that this material becomes rapidly recalcitrant because of selective depletion of simple sugars and accumulation of aromatic and aliphatic compounds (Bonanomi et al. 2011b). No positive BEF has been reported for woody sticks and cellulose strips, the organic substrates with the lower biochemical quality. It could be possible that, for these two materials, the time frame of the experiment was too short (120 days) to capture a significant effect of microbial diversity. When the two microbial groups were inoculated separately, different behaviours were observed: the synergistic interactions in microbial mixtures occur for both fungi and bacteria. We are not able to explain the different effects of fungal, bacteria and mixed inoculum and further studies are required to elucidate how microbial interactions are affected by changes in litter quality. Previous studies included only fungi (e.g., Bärlocher and Corkum 2003, Dang et al. 2005, Costantini and Rossi 2010) or bacteria (e.g., Bell et al. 2005, Jiang 2007, Langenheder et al. 2010), and we are aware of only one case where the two groups were used together (Setälä and McLean 2004). This is surprising considering that bacteria and fungi normally coexist over a wide range of decomposing organic materials and environmental conditions.
In addition to microbial functional groups, the number of inoculated species in mixtures also plays a significant role. When bacteria and fungi were co-inoculated on $H$. helix litter, in two cases the mixtures made by eight species performed better than mixtures composed by 1, 32 and 64 species. As a consequence, hump-shaped BEF relationships were evident when bacteria and fungi were co-inoculated. In a study that used simultaneously fungi and bacteria on raw humus (Setälä and McLean 2004) BEF already reached its maximum when only 3 to 6 species of fungi were inoculated in the microcosms, suggesting the existence of a considerable functional equivalency, or redundancy, among the decomposer fungi. The same result was obtained by Dang et al. (2005) using hyphomycete synthetic communities. Consistent with this finding, our study reported that BEF often saturated at the poor-end of the diversity gradient. However, in two cases, a decrease of the BEF at the rich-end of the diversity gradient occurred, suggesting that when many species are simultaneously present antagonistic interspecific interactions can take place. Similarly, Costantini and Rossi (2010) reported that hump-shaped BEF emerged for fungal hyphomycetes communities decomposing several types of leaf litter.

In relation to temporal dynamics, biodiversity effects may either increase or decrease during the course of the experiments (Tilman et al. 2001, Hooper and Duke 2004, Bell et al. 2005, Weis et al. 2007, Marquard et al. 2009, Langenheder et al. 2010). In our case, BEF showed a complex temporal dynamics, and no clear trend could be detected as litter decomposition proceeded. These changes are difficult to explain because in some cases BEF decreased, in other increased or remained unchanged. Biodiversity effects on litter mass loss are not consistent and the observed BEF variability may be related to the continuous changes of litter quality (Bonanomi et al. 2013) that, in turn, probably affects the net interactions among microbes. Further studies are required to shed light on this issue.

A number of studies discussed if positive BEF is due either to the statistical mechanism called sampling effect or to a real species complementarity (e.g., Huston 1997, Tilman 1999, Wardle 1999, Hooper et al. 2005). According to the first hypothesis, the positive BEF is associated with the dominance of a single best competitor in polycultures, and the probability that multi-species microbial consortia include such better competitor (Tilman 1999). In the second case, species complementarity may be due to niche resource partitioning among species and/or to the occurrence of interspecific facilitative interactions (Cardinale et al. 2002). "Sampling effect" and "species complementarity" could be statistically partitioned if performances of individual species in polycultures are tracked (Loreau and Hector 2001). However, this was not feasible in our study because litter decomposition by individual species was not measurable in multi-species microbial consortia. In addition, species richness into microcosms was not assessed and, consequently, species dominance in multispecies microbial consortia remains unknown. Keeping in mind such methodological caveats, we found that the most performing polycultures outperform the best monocultures in only 6 out of 34 cases (17.6\%). Moreover, in all 6 cases the multi-species microbial inoculums contained some of the best 
performing species in monocultures. Because strong species complementarity predicts that polycultures might outperform the best monoculture, our result suggests that the positive BEF observed are predominantly explained by the sampling effect, although complementarity could be operative in some specific microbial combinations. In a recent work, Langenheder et al. (2010), by using synthetically assembled bacterial communities, concluded that true complementarity effects were uncommon in their decomposition experiments.

Environmental variability, in terms of both biotic and abiotic factors, may greatly affect the shape of BEF (Hooper et al. 2005). In the present study, in addition to litter quality, incubation temperature greatly influenced the shape of BEF response. Pooling the results of the three experiments we found that at the highest incubation temperature $\mathrm{BEF}$ was positive in $75.0 \%$ of the cases ( 12 out of 18 cases). On the contrary, this value dropped to $16.6 \%$ at the lowest temperature ( 3 out of 18 cases). The prevalence of positive BEF at higher temperatures is noteworthy but difficult to explain with available data. Previous studies reported a positive effect of resources availability on BEF in other systems such as higher plants in relation to $\mathrm{CO}_{2}$ enrichment (Niklaus et al. 2001, Reich et al. 2001) and soil fertilization (Fridley 2002). Indeed, the prevalence of positive BEF for litter decomposition at high temperature needs further studies to assess the underlying mechanisms.

The relationships between diversity and stability of process rates have been debated in the last years (e.g., Tilman 1999, McCann 2000). This work showed that the variability of the decomposition processes was considerably reduced by increasing the inoculated microbial species richness. This was evident for litter mass loss when either fungal or bacterial communities were inoculated, as well as when fungi and bacteria were co-inoculated. Similar results about mass loss have been found for other ecosystems in which diversity of plant litter (Keith et al. 2008) as well as that of communities of synthetically assembled microbes (McGrady-Steed et al. 1997, Dang et al. 2005), mosses (Mulder et al. 2001), and vascular plants (Tilman 1996) were manipulated. The reduced variability among treatments observed in multi-species microbial consortia compared to monoculture could be due to a statistical averaging process, also called portfolio effect (Tilman et al. 1998). In other words, dominance by a single or few species with extreme high or low properties could be dampened in species-rich assemblages producing a more stable process rate. A lower variability by increasing community species richness can be important for the stability of ecosystem functioning (Hättenschwiler and Gasser 2005, Lecerf et al. 2007). In fact, species-rich microbial assemblages encompassing a broad spectrum of microbes with different properties could provide a less variable litter decomposition process and, consequently, a nutrient mineralization potentially beneficial for ecosystem functionality.

\section{Conclusions}

Our study confirmed the positive relationship between microbial diversity and stability of decomposition process.
Therefore, the loss of microbial species from an ecosystem may result in a reduction of effectiveness and stability of the decomposition process. The magnitude of such negative effect clearly depends on litter type and underlying environmental conditions. Because resource quality and abiotic environmental conditions significantly affected the shape of BEF, future studies should clarify the relationships between such ecological factors and species diversity.

Acknowledgments. We thank G. Puopolo for providing some bacterial strains and M. V. Ceniccola for technical support.

\section{References}

Aerts, R. 1997. Climate, leaf litter chemistry and leaf litter decomposition in terrestrial ecosystems: a triangular relationship. Oikos 79: 439-449.

Bärlocher, F. and Corkum, M. 2003. Nutrient enrichment overwhelms diversity effects in leaf decomposition by stream fungi. Oikos 101: 247-252.

Bell, T., Newman, J.A., Silverman, B.W., Turner S.L. and Lilley, A.K. 2005. The contribution of species richness and composition to bacterial services. Nature 436: 1157-1160.

Berg, B. and McClaugherty C. 2008. Plant litter: Decomposition, Humus Formation and Carbon Sequestration. Second edition. Springer-Verlag, Berlin, Heidelberg.

Boddy, L. 2000. Interspecific combative interactions between wooddecaying basidiomycetes - a review. FEMS Microb. Ecol. 31: 185-194.

Bonanomi, G., Incerti, G., Antignani, V., Capodilupo, M. and Mazzoleni, S. 2010. Decomposition and nutrient dynamics in mixed litter of Mediterranean species. Plant Soil 331: 481-496.

Bonanomi, G., D’Ascoli, R., Antignani, V., Capodilupo, M., Cozzolino, L., Marzaioli, R., Puopolo, G., Rutigliano, F.A., Scelza, R., Scotti, R., Rao, M.A. and Zoina A. 2011a. Assessing soil quality under intensive cultivation and tree orchards in Southern Italy. App. Soil Ecol. 47: 184-194.

Bonanomi, G., Incerti, G., Barile, E., Capodilupo, M., Antignani, V., Mingo, A., Lanzotti, V., Scala, F. and Mazzoleni, S. 2011b. Phytotoxicity, not nitrogen immobilization, explains plant litter inhibitory effects: evidence from solid-state ${ }^{13} \mathrm{C}$ NMR spectroscopy. New Phytol. 191: 1018-1030.

Bonanomi, G., Incerti, G., Giannino, F., Mingo, A., Lanzotti, V. and Mazzoleni, S. 2013. Litter quality assessed by solid state ${ }^{13} \mathrm{C}$ NMR spectroscopy predicts decay rate better than $\mathrm{C} / \mathrm{N}$ and Lignin/N ratios. Soil Biol. Biochem. 56: 40-49.

Cardinale, B.J., Palmer, M.A. and Collins, S.L. 2002. Species diversity enhances ecosystem functioning through interspecific facilitation. Nature 415: 426-429.

Costantini, M.L. and Rossi, L. 2010. Species diversity and decomposition in laboratory aquatic systems: the role of species interactions. Freshwater Biol. 55: 2281-2295.

Dang, C.K., Chauvet, E. and Gessner, M.O. 2005. Magnitude and variability of process rates in fungal diversity-litter decomposition relationships. Ecol. Lett. 8: 1129-1137.

Dilly, O., Bloem, J., Vos, A. and Munch, J.C. 2004. Bacterial diversity in agricultural soils during litter decomposition. App. Environ. Microb. 70: 468-474. 
Duarte, S., Pascoal, C., Cássio, F. and Bärlocher, F. 2006. Aquatic hyphomycete diversity and identity affect leaf litter decomposition in microcosms. Oecologia 147: 658-666.

Dukes, J.S. 2001. Biodiversity and invasibility in grassland microcosms. Oecologia 126: 563-568.

Frankland, J.C. 1966. Succession of fungi on decaying bracken petioles. J. Ecol. 57: 25-36.

Frankland, J.C. 1998. Fungal succession - unraveling the unpredictable. Mycol. Res. 102: 1-15.

Fridley, J.D. 2002. Resources availability dominates and alters the relationship between species diversity and ecosystem productivity in experimental plant communities. Oecologia 132: 271-277.

Garrett, S.D. 1963. Soil Fungi and Soil Fertility. Pergamon Press, Oxford, and Macmillan Co., NY.

Gessner, M.O. 2005. Proximate lignin and cellulose. In: Graca, M.A.S., Bärlocher, F., Gessner, M.O. (eds), Methods to Study Litter Decomposition. A Practical Guide. Springer Verlag, The Netherlands, pp. 115-120.

Griffiths, B.S., Ritz, K., Bardgett, R.D., Cook, R., Christensen, S., Ekelund, F., Sørensen, S.J., Bååth, E., Bloem, J., De Ruiter, P.C., Dolfing, J. and Nicolardot, B. 2000. Ecosystem response of pasture soil communities to fumigation-induced microbial diversity reductions: an examination of the biodiversity-ecosystem function relationship. Oikos 90: 279-294

Hättenschwiler, S., Tiunov A.V. and Scheu, S. 2005. Biodiversity and litter decomposition in terrestrial ecosystems. Annu. Rev. Ecol. Syst. 36: 191-218

Hättenschwiler, S. and Gasser, P. 2005. Soil animals alter plant litter diversity effects on decomposition. Proc. Natl. Acad. Sci. USA 102: 1519-1524.

Hooper, D.U., Chapin, F.S. III, Ewel, J.J., Hector, A., Inchausti, P., Lavorel, S., Lawton, J.H., Lodge, D.M., Loreau, M., Naeem, S., Schmid, B., Setala, H., Symstad, J., Vandermeer, J. and Wardle, D.A. 2005. Effects of biodiversity on ecosystem functioning: a consensus of current knowledge. Ecol. Monogr. 75: 3-35.

Hooper, D.U. and Dukes, J.S. 2004. Overyielding among plant functional groups in a long-term experiment. Ecol. Lett. 7: 95-105.

Huston, M.A. 1997. Hidden treatments in ecological experiments: re-evaluating the ecosystem function of biodiversity. Oecologia 110: 449-460

Jiang, L. and Morin, P.J. 2005. Productivity gradients cause positive diversity-invasibility relationships in microbial communities. Ecol. Lett. 7: 1047-1057.

Jiang, L. 2007. Negative selection effects suppress relationships between bacterial diversity and ecosystem functioning. Ecology 88: $1075-1085$.

Keith, A.M., Van Der Wal, R., Brooker, R.W., Osler, G.H.R., Chapman, S.J., Burslem, D.F.R.P. and Elston, D. 2008. Increasing litter species richness reduces variability in a terrestrial decomposer system. Ecology 89: 2657-2664.

Langenheder, S., Bulling, M.T., Solan, M. and Prosser, J.I. 2010. Bacterial biodiversity-ecosystem functioning relations are modified by environmental complexity. PLOS ONE 5: e10834.

Lecerf, A., Risnoveanu, G., Popescu, C., Gessner, M.O. and Chauvet, E. 2007. Decomposition of diverse litter mixtures in streams. Ecology 88: 219-227.

Loreau, M. and Hector, A. 2001. Partitioning selection and complementarity in biodiversity experiments. Nature 412: 72-76.

Marquard, E., Weigelt, A., Temperton, V.M., Roscher, C., Schumacher, J., Buchmann, N., Fischer, M., Weisser, W.W. and Schmid, B. 2009. Plant species richness and functional com- position drive overyielding in a six-year grassland experiment. Ecology 90: 3290-3302.

McCann, K.S. 2000. The diversity-stability debate. Nature 405: 228233.

McGrady-Steed, J., Harris, P.M. and Morin, P.J. 1997. Biodiversity regulates ecosystem predictability. Nature 390: 162-165.

Merritt, R. and Lawson, D. 1992. The role of leaf litter macroinvertebrates in stream-floodplain dynamics. Hydrobiologia 248: 65-77.

Moorhead, D.L. and Sinsabaugh, R.L. 2006. A theoretical model of litter decay and microbial interaction. Ecol. Monogr. 76: 151174.

Mulder, C.P.H., Uliassi, D.D. and Doak, D.F. 2001. Physical stress and diversity-productivity relationships: the role of positive interactions. Proc. Natl. Acad. Sci. USA 98: 6704-6708.

Naeem, S, Thompson, L.J., Lawier, S.P., Lawton, J.H. and Woodfin, R.M. 1994. Declining biodiversity can alter the performance of ecosystems. Nature 368: 734-737.

Niklaus, P.A., Leadley, P.W., Schmid, B. and Körner, C. 2001. A long-term study on biodiversity $\times$ elevated $\mathrm{CO}_{2}$ interactions in grassland. Ecol. Monogr. 71: 341-356.

Osono, T. 2003. Effects of prior decomposition of beech leaf litter by phyllosphere fungi on substrate utilization by fungal decomposers. Mycoscience 44: 41-45.

Preston, C.M., Nault, J.R. and Trofymow, J.A. 2009. Chemical changes during 6 years of decomposition of 11 litters in some Canadian forest sites. Part $2 .{ }^{13} \mathrm{C}$ abundance, solid-state ${ }^{13} \mathrm{C}$ NMR spectroscopy and the meaning of "lignin". Ecosystems 12: $1078-1102$

Reich, P.B., Knops, J., Tilman, D., Craine, J.,. Ellsworth, D., Tjoelker, M., Lee, T.,. Wedin, D., Naeem, S., Bahauddin, D., Hendrey, G., Jose, S., Wrage, K., Goth, J. and Bengston, W. 2001. Plant diversity enhances ecosystem responses to elevated $\mathrm{CO}_{2}$ and nitrogen deposition. Nature 410: 809-812.

Replansky, T. and Bell, G. 2009. The relationship between environmental complexity, species diversity and productivity in a natural reconstructed yeast community. Oikos 118: 233-239.

Rinkes, Z.L., Weintraub, M.N., DeForest, J.L. and Moorhead, D.L. 2011. Microbial substrate preference and community dynamics during decomposition of Acer saccharum. Fungal Ecol. 4: 396407.

Romaní, A.M., Fischer, H., Miller-Lindblom, C. and Tranvik, L.J. 2006. Interactions of bacteria and fungi on decomposing litter: differential extracellular enzyme activities. Ecology 87: 25592569

Setälä, H. and McLean, M.A. 2004. Decomposition rate of organic substrates in relation to the species diversity of soil saprophytic fungi. Oecologia 139: 98-107.

Srivastava, D.S. and Vellend, M. 2005. Biodiversity-ecosystem function research: is it relevant to conservation? Annu. Rev. Ecol. Syst. 36: 267-294.

Swift, M.J., Heal, O.W. and Anderson, J.M. 1979. Decomposition in Terrestrial Ecosystems. Studies in Ecology 5. Blackwell Scientific Publications, Oxford.

Tilman, D. 1996. Biodiversity: population versus ecosystem stability. Ecology 77: 350-363.

Tilman, D. 1999. The ecological consequences of changes in biodiversity: A search for general principles. Ecology 80: 1455-1474.

Tilman, D., Lehman, C.L. and Bristow, C.E. 1998. Diversity-stability relationships: statistical inevitability or ecological consequence? Am. Nat. 151: 277-282. 
Tilman, D., Reich, P.B., Wedin, D., Mielke, T. and Lehman, C. 2001. Diversity and productivity in a long-term grassland experiment. Science 294: 843-845.

Tilman, D., Wedin, D. and Knops, J. 1996. Productivity and sustainability influenced by biodiversity in grassland ecosystems. Nature 379: 718-720.

Tiunov, A.V. and Scheu, S. 2005. Facilitative interactions rather than resource partitioning drive diversity-functioning relationships in laboratory fungal communities. Ecol. Lett. 8: 618-625.

Wallace, J.B., Eggert, S.L., Meyer, J.L. and Webster, J.R. 1997. Multiple trophic levels of a forest stream linked to terrestrial litter inputs. Science 277(5322): 102-104.

Wardle, D.A. 1999. Is "sampling effect" a problem for experiments investigating biodiversity-ecosystem function relationships? Oikos 87: 403-407.

Weis, J.J., Cardinale, B.J., Forshay, K.J. and Ives, A.R. 2007. Effects of species diversity on community biomass production change over the course of succession. Ecology 88: 929-939.

Weller, D.M., Raaijmakers, J.M., Gardener, B.B.M. and Thomashow, L.S. 2002. Microbial population responsible for specific soil suppressiveness to plant pathogens. Апnи Rev. Phytopathol. 40: 309-349.
White, T.J., Bruns, T.D., Lee, S. and Taylor, J. 1990. Amplification and direct sequencing of fungal ribosomal RNA genes for phylogenetics. In: White, T.J., Sninsky, J.J., Gelfand, D.H., Innin, M.A. (eds.), PCR Protocols - A Guide to Methods and Applications. Academic Press, San Diego, USA, pp. 315-322.

Wragg, P., Randall, L. and Whatmore, A.M. 2014. Comparison of Biolog GEN III MicroStation semi-automated bacterial identification system with matrix-assisted laser desorption ionizationtime of flight mass spectrometry and 16S ribosomal RNA gene sequencing for the identification of bacteria of veterinary interest. J. Microbiol. Met. 105: 16-21.

Received June 14, 2014

Revised May 10, 2015

Accepted June 13, 2015

\section{Electronic supplements}

Tables S1-S4.

The file may be downloaded from www.akademiai.com 